Article

Subscriber access provided by King Abdullah University of Science and Technology Library

\title{
Benzo[1,2-b:4,5-b']dithiophene-Pyrido[3,4-b]pyrazine Small-Molecule Donors for Bulk Heterojunction Solar Cells
}

Jannic Wolf, Maxime Babics, Kai Wang, Qasim Saleem, Ru-

Ze Liang, Michael Ryan Hansen, and Pierre M. Beaujuge

Chem. Mater., Just Accepted Manuscript • DOI: 10.1021/acs.chemmater.5b04726 • Publication Date (Web): 22 Jan 2016

Downloaded from http://pubs.acs.org on January 27, 2016

\section{Just Accepted}

"Just Accepted" manuscripts have been peer-reviewed and accepted for publication. They are posted online prior to technical editing, formatting for publication and author proofing. The American Chemical Society provides "Just Accepted" as a free service to the research community to expedite the dissemination of scientific material as soon as possible after acceptance. "Just Accepted" manuscripts appear in full in PDF format accompanied by an HTML abstract. "Just Accepted" manuscripts have been fully peer reviewed, but should not be considered the official version of record. They are accessible to all readers and citable by the Digital Object Identifier (DOI®). "Just Accepted" is an optional service offered to authors. Therefore, the "Just Accepted" Web site may not include all articles that will be published in the journal. After a manuscript is technically edited and formatted, it will be removed from the "Just Accepted" Web site and published as an ASAP article. Note that technical editing may introduce minor changes to the manuscript text and/or graphics which could affect content, and all legal disclaimers and ethical guidelines that apply to the journal pertain. ACS cannot be held responsible for errors or consequences arising from the use of information contained in these "Just Accepted" manuscripts. 


\section{Introduction}

Recent studies have shown that solution-processable $\pi$ conjugated small-molecule (SM) donors used in bulk heterojunction $(\mathrm{BHJ})$ solar cells with fullerene acceptors can rival their polymer donor counterparts, yielding device efficiencies $>6 \%{ }^{1-4}$ and as high as ca. $10 \% .^{5}$ Compared to polymers, SM systems have a well-defined, finite conjugation length and molecular weight, and they can be purified via conventional chromatography or recycling HPLC/SEC techniques - clear benefits that minimize batch-to-batch variations and lessen scalability issues. In parallel, solution-processed SMs can achieve higher short-range and mesoscale ordering than polymers, ${ }^{6-9}$ and since $\mathrm{BHJ}$ active layers with high carrier mobilities can yield improved figures of merit (i.e. short-circuit current, $J_{\mathrm{SC}}$ and fill-factor, $\left.F F\right),{ }^{10-12}$ these correlated material properties make SMs particularly attractive on the path to raising the practical efficiency limits of organic photovoltaics (OPVs).

Some of the best-performing SM systems in BHJ solar cells with fullerene acceptors rely on donor-acceptor dithieno[3,2-b:2',3'-d]silole-benzo[c][1,2,5]thiadiazole building motifs ${ }^{1,4}$ and oligothiophene sequences capped with relatively electron-withdrawing units, such as rhodanine. ${ }^{13-15}$ As with polymer donors, the types and sequences of donor and acceptor motifs used along the
SM backbone impact their optical, electronic (e.g. ionization potential, bandgap, $\pi$-electron delocalization and orbital overlap) ${ }^{14,16-17}$ and self-assembling properties in thin films, ${ }^{18-19}$ in turn resulting in distinct efficiency patterns in BHJ solar cells. In addition, the set of solubilizing side chains appended to the SM backbone must allow for adequate solution-processability and mitigated aggregation, while preserving favorable packing effects that help promote self-assembly, $\pi-\pi$ stacking, and in turn charge transport across the $\mathrm{BHJ}$ active layers. In parallel, the solution-processing conditions (e.g. use of additives, ${ }^{1,2,20}$ nucleating agents, ${ }^{21}$ solvent type,$\left.{ }^{1,11}\right)$ and post-processing treatments (e.g. thermal ${ }^{2,22-23}$ and solvent annealing ${ }^{24-25}$ ) used in the optimization of SM-based BHJ solar cell performance induces important morphological effects that set the device efficiency baseline and help leverage optimal figures of merit. ${ }^{7,19,26}$ However, it is critical to note that most SM systems do not readily achieve power conversion efficiencies (PCEs) $>6 \%$, even upon careful, systematic BHJ device optimizations, ${ }^{22,27-30}$ and the molecular structure of SMs remains the determining factor directing material performance and $\mathrm{BHJ}$ solar cell efficiency.

While benzo[c][1,2,5]thiadiazole and its nitrogen- or fluorine-substituted analogues have frequently been used as acceptor motifs in the design of low-bandgap SM donors, these units lack synthetic modularity and solubilizing side chains cannot be easily derived. ${ }^{31-33}$ In contrast, 
quinoxaline $\mathrm{s}^{3-37}$ and pyrido $[3,4-b]$ pyrazine $(\mathrm{PP})$ motifs are more synthetically tunable and can be made with alkyl side-chain substituents that can contribute towards solubility, yet PP units have seen only limited use thus far. Following the first account of PP units used in polymers for electrochromic applications, ${ }^{38}$ a few studies have turned to PP motifs (or analogues) in the design of donoracceptor polymers for BHJ solar cells. ${ }^{39-42}$ Among those, fused bibenzo[a,c]phenazine units copolymerized with indacenodithiophene, ${ }^{43}$ and a phenyl-substituted analogue copolymerized with thiophene, ${ }^{39}$ have led to polymer donors with promising PCEs in the range of $3-4 \%$ in $\mathrm{BHJ}$ devices with fullerene acceptors. PP-based $\pi$ conjugated systems have occasionally been considered for dye sensitized solar cell (DSSC) $)^{3,44-46}$ or two-photon absorption ${ }^{47}$ studies, but PP motifs remain practically unexplored in SM designs for BHJ solar cells.

In this contribution, we report on the synthesis, properties and $\mathrm{BHJ}$ solar cell characteristics of a set of four benzo[1,2- $\left.b: 4,5-b^{\prime}\right]$ dithiophene-pyrido[3,4-b]pyrazine SM donors with alkyl-substituted bithiophene end groups (SM1-4, Chart 1). In these systems, BDT and PP motifs replace their dithieno[3,2-b:2',3'-d]silole and (N- or Fsubstituted) benzo[c] $[1,2,5]$ thiadiazole analogues commonly used in prior SM studies, ${ }^{1-2}$ but the general donoracceptor sequence remains analogous for direct comparisons. Importantly, we show that both the type of sidechain substituents on the PP motifs and the presence of ring-substituents on BDT critically impact (i) molecular packing, and (ii) thin-film morphologies and charge transport in $\mathrm{BHJ}$ solar cells made with SM1-4 and phenyl$C_{71}$-butyric acid methyl ester $\left(\mathrm{PC}_{71} \mathrm{BM}\right)$ as the fullerene acceptor. While device PCEs remain <3\% with SM1-3, optimized $\mathrm{BHJ}$ solar cells made with the ring-substituted (BDT(T)) counterpart $\mathrm{SM}_{4}$ achieve up to ca. 6.5\% PCE, and fine-scale thin-film morphologies that are comparable to those obtained with some of the best-performing polymer donors used together with $\mathrm{PC}_{71} \mathrm{BM} \cdot{ }^{48-50}{ }^{1} \mathrm{H}-{ }^{1} \mathrm{H}$ double quantum-single quantum (DQ-SQ) NMR analyses are used to examine the distinct self-assembly pattern of $\mathrm{SM}_{4}$, which can be expected to factor into the development of the $\mathrm{BHJ}$ morphology with $\mathrm{PC}_{71} \mathrm{BM}$. In comparison with the low-bandgap dithieno[3,2- $\left.b: 2^{\prime}, 3^{\prime}-d\right]$ silolebenzo[c] $[1,2,5]$ thiadiazole (N- or F-substituted) SM analogues $\left(E_{\mathrm{opt}} \sim \mathbf{1 . 5} \mathrm{eV}\right)$, benzo[1,2-b:4,5- $\left.b^{\prime}\right]$ dithiophenepyrido[3,4-b]pyrazine SM donors are wider-bandgap $\left(E_{\text {opt }} \sim 1.9 \mathrm{eV}\right.$; similar to that of $\left.\mathrm{P}_{3} \mathrm{HT}^{51-52}\right)$ and promising systems for use in the high-bandgap cell of SM multijunction devices with complementary absorbers.

\section{Results and Discussion Design and Synthesis}

The convergent synthetic route described in Scheme 1 shows how solubilizing side chain permutations are made possible across the set of SM donors, SM1-4. The 2,3dialkylpyrido[3,4- $b]$ pyrazine acceptor motifs were synthesized from the 4-amino-3-nitropyridine precursor (1). Near-quantitative reduction (97\%) of 1 to the diamine intermediate $\mathbf{2}$, followed by regioselective bromination $(60 \%)$ yields to intermediate 3 , which is then cyclized by
Chart 1. Benzo[1,2-b:4,5-b']dithiophene-pyrido[3,4-b]pyrazine SM Donors, SM1-4.

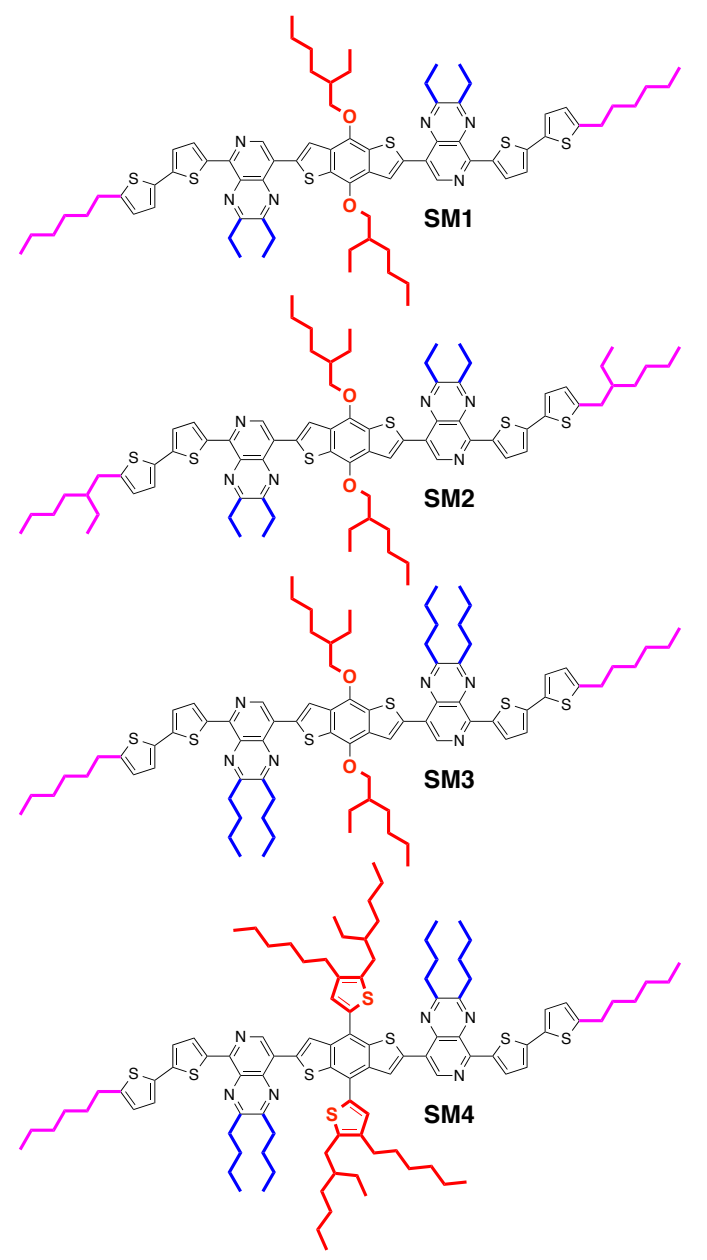

condensation with alkyl diones to form the PP motifs $\mathbf{4 a} / \mathbf{b}$ in relatively high yields ( $86 \%$ and $72 \%$, respectively). Stannylation of the alkyl-substituted bithiophene end groups $\mathbf{5 a / b}$ (ca. 90\%) leads to the coupling partners $\mathbf{6 a} / \mathbf{b}$, which are then engaged in a microwave-assisted Stille-type Pd cross-coupling reaction with the PP motifs $\mathbf{4 a / b}$ in toluene (see details in the Supporting Information, SI), yielding the intermediate building blocks $7^{\mathbf{a}} \mathbf{-}$ c $(50-60 \%)$ with distinct patterns of alkyl side-chain substituents. Importantly, the regioselectivity of the Pdmediated coupling between $4 \mathbf{a} / \mathbf{b}$ and $\mathbf{6 a} / \mathbf{b}$ is directed by the nitrogen heteroatoms in the unsymmetrical PP motifs, in consistency with the directing effects of nitrogen and fluorine discussed in prior reports on the lowbandgap dithieno[3,2-b:2',3'-d] silolebenzo[ $[c][1,2,5]$ thiadiazole SM analogues. ${ }^{1}$ Lastly, intermediate building blocks $7 \mathbf{a}-\mathbf{c}$ were coupled with the BDT or BDT(T) motifs $\mathbf{8 a} / \mathbf{b}$ by microwave-assisted Pd crosscoupling, producing SM1-4 in satisfying yields (6o-8o\%) after sequential purifications via column chromatography and recycling SEC (see details in SI). The regiochemistry of the Stille coupling reaction between $4 \mathbf{a} / \mathbf{b}$ and $\mathbf{6 a} / \mathbf{b}$ was confirmed by 2 D-NOESY spectroscopy analyses carried out on SM1-4; Figure $\mathrm{S}_{43}-46$ in the SI emphasizes the aromatic regions of the NOESY spectra where the appropriate correlations are observed. 
Scheme 1. Syntheses of the SM Donors, SM1-4.

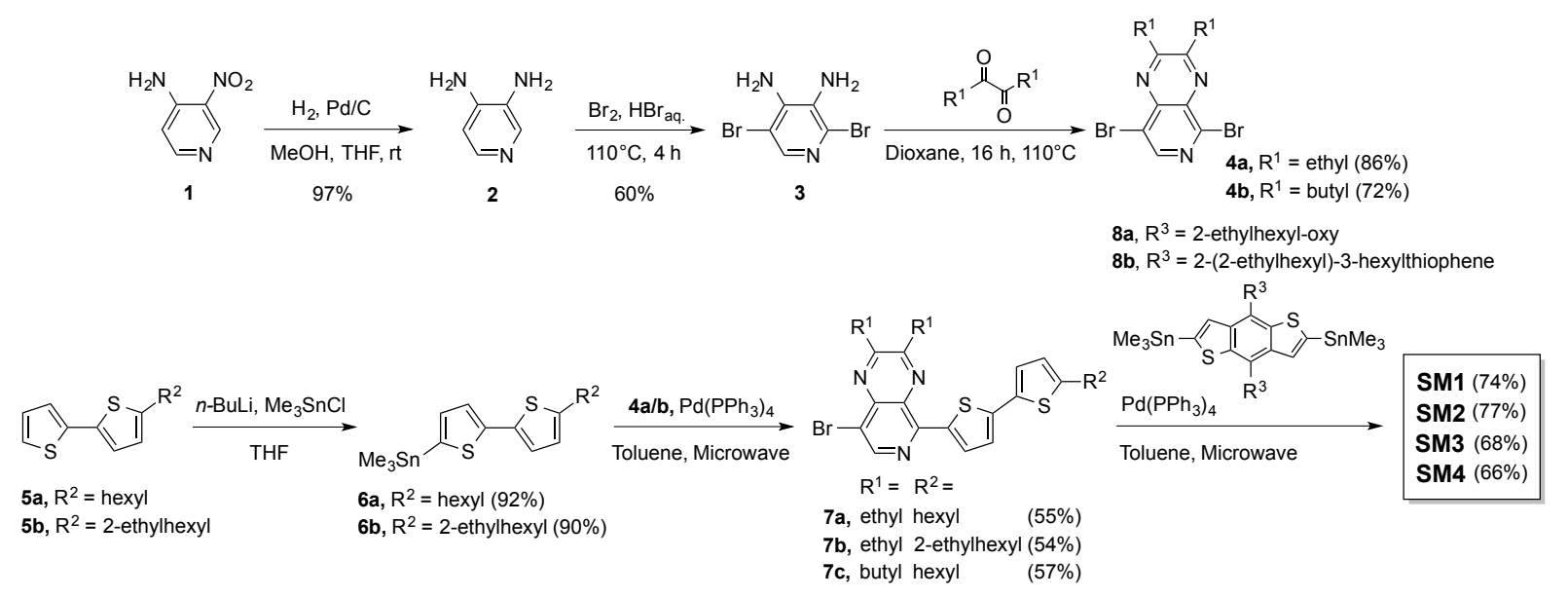

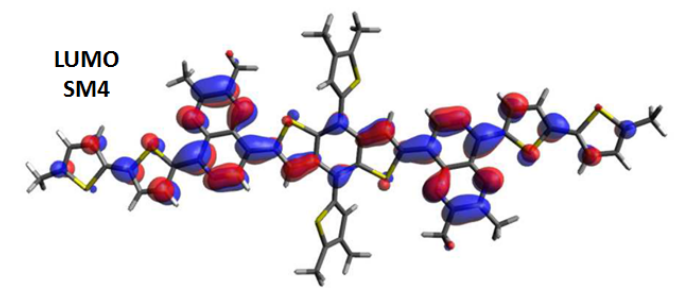

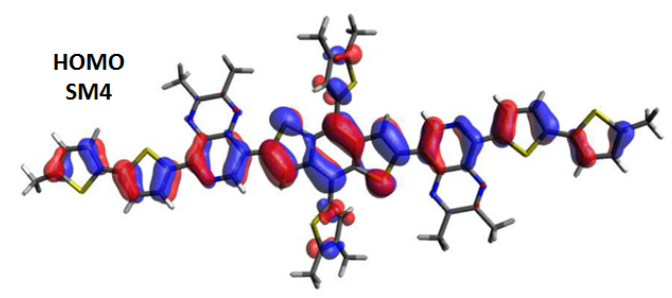

Figure 1. Representations of the HOMO and LUMO of $\mathbf{S M}_{\mathbf{4}}$ obtained by DFT at the B3LYP/6-31G(d,p) level of theory (see representation of SM1-3 in SI; Fig. S1. The modeled frontier orbitals emphasize $\pi$-electron delocalization and localization effects across the SM donor.

First-level density functional theory (DFT) calculations show that the benzo[1,2-b:4,5- $\left.b^{\prime}\right]$ dithiophene-pyrido[3,4$b$ ]pyrazine SM donor structures are expected to be relatively planar and their $\pi$-system well delocalized in the ground state (see $\mathrm{HOMO}$ of $\mathbf{S M}_{4}$ in Figure 1); DFT at the B3LYP/6-31G(d,p) level with Gaussian o9 (Revision C.o1) (cf. details in SI). Although side chains play an important role in molecular self-assembly, it is commonly assumed that the electronic properties and backbone geometry of single isolated $\pi$-conjugated systems are well represented in gas phase calculations where side chains are swapped for methyl groups (to optimize computational time). From these calculations, we estimate dihedral angles of $15-16^{\circ}$ between the BDT(T) and PP motifs; conformation in which the pyrazine moiety of PP is syn to the sulfur heteroatoms of adjacent thienyl motifs shown in Figure 1. The potential energy surfaces (PES) resulting from the rotation of the PP motifs with respect to BDT(T) and single-ring $\mathrm{T}$ units are represented in Figure $\mathrm{S} 2$ (cf. details in SI), showing that relative backbone planarity in $\mathbf{S M}_{\mathbf{4}}$ is achieved via statistical syn and anti conformations. The significant energetic barriers of ca. $3 \mathrm{kcal} \mathrm{mol}^{-1}$ (Fig. S2a) and $8 \mathrm{kcal} \mathrm{mol}^{-1}$ (Fig. S2b) on going from anti to syn conformations parallels the idea that the backbone of $\mathbf{S M}_{\mathbf{4}}$ is expected to remain rather coplanar (i.e. disfavoring "outof-plane" conformations); for reference, we note that $R T$ at room temperature $(298 \mathrm{~K})$ is approximately $0.6 \mathrm{kcal}$ $\mathrm{mol}^{-1}$, and that the energetic barriers discussed above are expected to prohibit inter-conversion between syn and anti conformers at room temperature. While the HOMO of all systems was found to be well delocalized across the $\pi$-conjugated backbones, we note that some localization on PP motifs occurs in the LUMO (Figure 1), with significant quinoidal character induced across the structure as the aromaticity of the pyrazine moieties of the PP motifs competes with main chain conjugation. In these systems, the HOMO $\rightarrow$ LUMO transition is expected to possess at least partial charge transfer character because of the differences in localization patterns between HOMO and LUMO.

\section{Material Properties}

The solution and thin-film UV-vis absorption spectra of SM1-4 are overlaid in Figure 2a-d. All four SM systems show comparable solution spectra, with near-equivalent molar absorptivity coefficients at their absorption peak: ca. $65400 \mathrm{~L} \mathrm{~mol}^{-1} \mathrm{~cm}^{-1}$ for SM1, ca. $61400 \mathrm{~L} \mathrm{~mol}^{-1} \mathrm{~cm}^{-1}$ for $\mathrm{SM}_{2}$ and $\mathrm{SM}_{3}$, and $c a$. $58200 \mathrm{~L} \mathrm{~mol}^{-1} \mathrm{~cm}^{-1}$ for $\mathrm{SM}_{4}$. The absence of long-wavelength absorption shoulders in the solution spectra of all SM donors indicate that the molecules are not prone to $\pi$-aggregate formation at the concentration of this experiment $\left(2 \times 10^{-5} \mathrm{M}\right)$. In thin films, the spectral absorption of all SMs shifts to longer wavelengths, with onsets shifting from ca. $615 \mathrm{~nm}$ in solution, to $>650 \mathrm{~nm}$ in thin films (up to $685 \mathrm{~nm}$ for $\mathrm{SM}_{3}$ ). The spectral features of the main absorption band and the $\pi$ aggregation footprint visible at longer wavelengths mark the propensity of the SMs to self-assemble in thin films (molecular packing effects will be discussed further in the next sections). Expectedly, the optical bandgap $\left(E_{\text {opt }}\right)$ values inferred from the onsets of thin-film absorption fall within the same range: $1.88 \mathrm{eV}$ for SM1, $1.86 \mathrm{eV}$ for SM2, $1.81 \mathrm{eV}$ for $\mathbf{S M}_{3}$, and $1.87 \mathrm{eV}$ for SM4. The ionization potentials (IPs) of SM1-4 were determined via photoelectron spectroscopy in air (PESA): $5.02 \mathrm{eV}$ for SM1, $5.09 \mathrm{eV}$ for $\mathbf{S M 2}_{2}$, $55 \mathrm{eV}$ for $\mathbf{S M}_{3}$, and 5.10 eV for $\mathbf{S M}_{4}$; expectedly 
comparable IP values, slightly larger than the HOMO energy levels of ca. 4.7 eV inferred from our prior DFT calculations (predicted HOMO-LUMO gap of $2.2 \mathrm{eV}$ ).
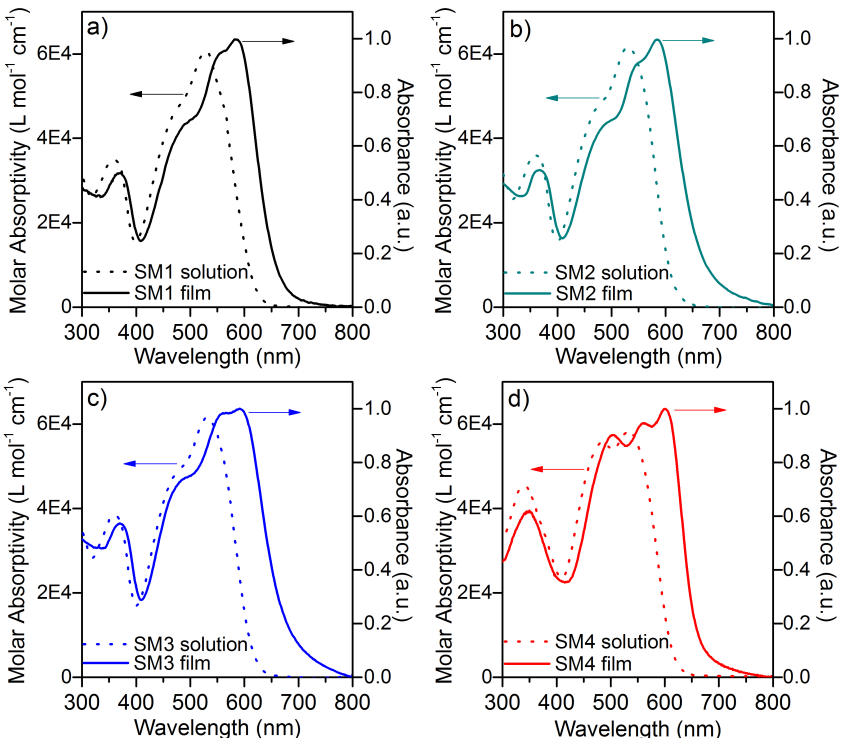

Figure 2. Superimposed solution (given in molar absorptivity; doted line) and thin-film (normalized; straight line) UV-Vis absorption spectra of (a) SM1, (b) SM2, (c) $\mathbf{S M}_{3}$ and (d) $\mathbf{S M}_{4}$. Solution spectra for concentrations of $2 \times 10^{-5}$ $\mathrm{M}$ in $\mathrm{CHCl}_{3}$.

The thermogravimetric analyses (TGA) given in Figure $\mathrm{S}_{3}$ show that the SM donors SM1-3 are thermally stable in nitrogen atmosphere until ca. $300{ }^{\circ} \mathrm{C}$ (ca. $5 \%$ weight loss observed at $335{ }^{\circ} \mathrm{C}$; ca. $17 \%$ weight loss at ca. $400{ }^{\circ} \mathrm{C}$ ). The onset of decomposition of SM1-3 can be assigned to the loss of the BDT alkoxy side chains, while the ringsubstituted counterpart $\mathbf{S M}_{4}$ involving $\mathrm{BDT}(\mathrm{T})$ motifs shows significantly improved thermal stability, with an onset of decomposition at ca. $400^{\circ} \mathrm{C}$ (ca. $5 \%$ weight loss observed at $432{ }^{\circ} \mathrm{C}$ ). The differential scanning calorimetry (DSC) analyses and polarized optical microscopy (POM) images shown in Figures 3, $\mathrm{S}_{4}$ and $\mathrm{S}_{5}$ show complex characteristic phase transition behaviors, with sharp melting transitions on the heating scans in a wide range of temperatures $\left(197{ }^{\circ} \mathrm{C}\right.$ for $\mathbf{S M 1}, 234{ }^{\circ} \mathrm{C}$ for $\mathbf{S M 2}, 173{ }^{\circ} \mathrm{C}$ for $\mathbf{S M}_{3}$, and $154{ }^{\circ} \mathrm{C}$ for $\mathbf{S M}_{4}$ ), indicating that the side-chain substitution patterns critically impact the physical properties of the SM donors. While the delayed crystallization transition of $\mathrm{SM}_{4}$ is observed at $76^{\circ} \mathrm{C}$ in Figure $3 \mathrm{a}$, the solidification/crystallization transitions are not always obvious from the cooling scans (cf. details in SI, including $1^{\text {st }}$ and $2^{\text {nd }}$ cycles), despite our effort to carefully characterize those systems using various conditions and scan rates. Figures $3 \mathrm{~b}-\mathrm{d}$ show the transition from highly crystalline films of $\mathrm{SM}_{4}$ to the isotropic melt state (the morphology depicted in Fig. $3 \mathrm{c}$ suggests that a mesophase may be achieved within range of the melting transition; $\mathrm{cf}$. additional details in SI, including $1^{\text {st }}$ and $2^{\text {nd }}$ DSC cycles). In parallel, we note that $\mathbf{S M}_{3}$ showed more apparent liquidcrystal characteristics (in the range $100-170{ }^{\circ} \mathrm{C}$, cf. details in SI).
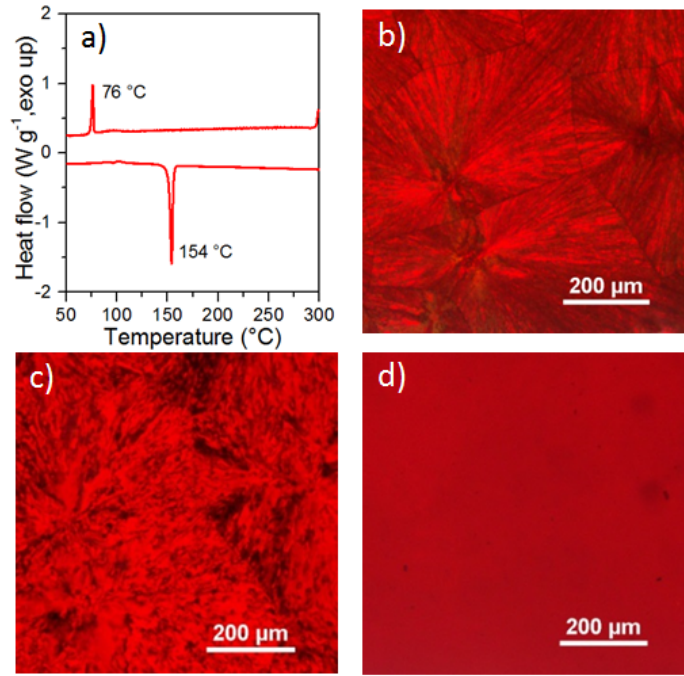

Figure 3. (a) Differential scanning calorimetry (DSC) trace of $\mathrm{SM}_{4}$ measured at a scan rate of $10 \mathrm{~K} \mathrm{~min}^{-1}$. The first heating (bottom, endo scan) and cooling (top, exo scan) cycle is shown; the SM sample was prepared under freeze-dry conditions (cf. details on the DSC analyses in SI). (b-d) Polarized optical microscopy (POM) images of $\mathrm{SM}_{4}$ on going from highly crystalline films to the isotropic melt state (through apparent mesophase); analyses performed with crossed-polarizers: (b) rt. $-155^{\circ} \mathrm{C}$, (c) 156 $-159{ }^{\circ} \mathrm{C}$, and $(\mathrm{d})>160{ }^{\circ} \mathrm{C}$.

\section{Device Testing and Characterizations}

Thin-film BHJ solar cells with the conventional device structure ITO/ $\mathrm{MoO}_{3} / \mathrm{SM}: \mathrm{PC}_{71} \mathrm{BM} / \mathrm{Ca} / \mathrm{Al}$ (device area: o.1 $\mathrm{cm}^{2}$ ) were fabricated and tested under AM1.5G solar illumination $\left(100 \mathrm{~mW} / \mathrm{cm}^{2}\right)$. The cells with optimized $\mathrm{SM}: \mathrm{PC}_{71} \mathrm{BM}$ blend ratios (1:1, wt/wt) were cast from chlorobenzene $(\mathrm{CB})$ (cf. details in SI, film thicknesses in the range of $75-85 \mathrm{~nm}$ ). As shown in Table 1 (device statistics provided in the SI, Table S2), "as-cast" devices made from SM1 did not show any significant promise (Avg. PCE= $0.5 \%)$, yielding concurrently low $J_{\mathrm{SC}}\left(2.2 \mathrm{~mA} / \mathrm{cm}^{2}\right)$ and $F F$ $(36 \%)$ values. In these devices, the $V_{\mathrm{OC}}$ of ca. $0.6 \mathrm{~V}$ is substantially lower than the expected figure of ca. $0.8 \mathrm{~V}$ based on the PESA-estimated IP of SM1 (ca. 5.0 eV), suggesting serious morphological limitations in the bulk of the active layer and/or at the contact interfaces. Optimized devices made from blends containing $1 \%(\mathrm{v} / \mathrm{v})$ of the processing additive 1,8-diiodooctane (DIO), showed improved $V_{\mathrm{OC}}(0.75 \mathrm{~V})$ in better agreement with the IP of $\mathrm{SM}$, higher $J_{\mathrm{SC}}\left(6.7 \mathrm{~mA} / \mathrm{cm}^{2}\right)$ and $F F(42 \%)$, and reached PCEs of $2.5 \%$ (Max.). Small-molecule additives, such as DIO and 1-chloronaphthalene $(\mathrm{CN})$, have been shown to improve the blend morphologies of SM-fullerene $\mathrm{BHJ}$ solar cells, and in turn device PCEs ${ }^{2,15}$ - although, we note that those improvements are not systematic and remain SM system-dependent. Considering solubility limitations and excess aggregation as possible grounds for the low efficiencies measured with SM1, we turned to the $\mathbf{S M 2}$ counterpart with branched 2-ethylhexyl-substituted bithiophene end groups (as opposed to linear $n$-hexyl). However, as shown in Table 1, optimized BHJ devices made with the slightly more soluble derivative $\mathbf{S M 2}$ did not outperform those made with SM1, yielding reduced 
Table 1. PV Performance of the SM Donors SM1-4 in Direct BHJ Devices with $\mathrm{PC}_{71} \mathrm{BM}^{a, b}$

\begin{tabular}{ccccccc}
$\mathrm{SM}$ & $\begin{array}{c}\mathrm{DIO} \\
\%(\mathrm{v} / \mathrm{v})\end{array}$ & $\begin{array}{c}J_{\mathrm{sc}} \\
{\left[\mathrm{mA} \mathrm{cm}^{-2}\right]}\end{array}$ & $\begin{array}{c}V_{\text {oc }} \\
{[\mathrm{V}]}\end{array}$ & $\begin{array}{c}\text { FF } \\
{[\%]}\end{array}$ & $\begin{array}{c}\text { Avg. } \\
\text { PCE } \\
{[\%]}\end{array}$ & $\begin{array}{c}\text { Max. } \\
\text { PCE } \\
{[\%]}\end{array}$ \\
\hline $\mathrm{SM} 1$ & 0 & 2.2 & 0.62 & 36 & 0.5 & 0.7 \\
$\mathrm{SM}^{c}$ & 1.0 & 6.7 & 0.75 & 42 & 2.1 & 2.5 \\
\hline $\mathrm{SM}_{2}$ & 0 & 1.6 & 0.65 & 33 & 0.3 & 0.5 \\
$\mathrm{SM}_{2}{ }^{c}$ & 0.5 & 3.6 & 0.71 & 37 & 0.9 & 1.0 \\
\hline $\mathrm{SM}_{3}$ & 0 & 2.1 & 0.66 & 36 & 0.5 & 0.7 \\
$\mathrm{SM}_{3}{ }^{c}$ & 0.5 & 5.7 & 0.81 & 49 & 2.3 & 2.5 \\
\hline $\mathrm{SM}_{4}$ & 0 & 7.0 & 0.95 & 36 & 2.4 & 2.6 \\
$\mathrm{SM}_{4}{ }^{c}$ & 0.2 & 10.5 & 0.90 & 67 & 6.3 & 6.5 \\
\hline
\end{tabular}

${ }^{a}$ Devices with optimized SM:PC ${ }_{71} \mathrm{BM}$ ratio of $1: 1$ (wt/wt) solution-cast from chlorobenzene (CB). ${ }^{b}$ Additional device statistics, including standard deviations, are provided in the SI (Fig. S4). ${ }^{c}$ Optimized device conditions.

$J_{\mathrm{SC}}\left(3.6 \mathrm{~mA} / \mathrm{cm}^{2}\right), F F \quad(37 \%)$ and PCEs of 1.0\% (Max.). Swapping linear side chains ${ }^{53-55}$ for branched ones to impart more solubility influences molecular packing and can sometimes be detrimental to material performance. In an alternative effort to impart greater solubility to the SM donors, in $\mathbf{S M}_{3}$, the ethyl side chains on the PP motifs were swapped for the longer $n$-butyl substituents. As shown in Table 1, optimized BHJ devices made with $\mathbf{S M}_{3}$ showed significantly improved $V_{\mathrm{OC}}(\mathrm{o.81} \mathrm{V})$ and $F F(49 \%)$, yet modest $J_{\mathrm{SC}}\left(5.7 \mathrm{~mA} / \mathrm{cm}^{2}\right)$ and, in turn, PCEs of $2.5 \%$ (Max.) equivalent to those achievable with SM1. The BHJ morphologies of "as-cast" and optimized devices made from $\mathbf{S M}_{3}$ were inspected by bright-field electron transmission microscopy (TEM; cf. details in SI). Significant differences in phase separation patterns are known to impact SM-fullerene BHJ solar cell performance. ${ }^{56-57}$ Here, the TEM images in Figure $5 \mathrm{a}$ and $5 \mathrm{~b}$ show a net degree of phase separation on ca. $100 \mathrm{~nm}$ (Avg.) length scales (especially pronounced in "as-cast" devices). In bright-field TEM, the darker areas are attributed to the fullerene-rich regions, here interconnected via a network of SM-rich boundaries. The coarse phase separation seen in the "ascast" blend films of $\mathbf{S M}_{3}$ and $\mathrm{PC}_{71} \mathrm{BM}$ is likely to limit the efficiency of exciton diffusion to the SM-fullerene interfaces, in turn yielding low device photocurrents and poor $\mathrm{BHJ}$ solar cell efficiencies. While the use of $0.5 \%$ DIO $(\mathrm{v} / \mathrm{v})$ appears to mitigate the phase-segregated pattern in optimized $\mathrm{BHJ}$ devices, distinct $\mathrm{SM}$ - and $\mathrm{PC}_{71} \mathrm{BM}$-rich domains subsist, and the $J_{\mathrm{SC}}\left(5.7 \mathrm{~mA} / \mathrm{cm}^{2}\right)$ and PCEs (Max. $\mathbf{2 . 5} \%$ ) remain modest.

Our effort to further improve SM solubility and miscibility between our benzo[1,2-b:4,5- $\left.b^{\prime}\right]$ dithiophenepyrido $[3,4-b]$ pyrazine SM donors and $\mathrm{PC}_{71} \mathrm{BM}$ led to $\mathbf{S M}_{\mathbf{4}}$, in which the central BDT unit bears alkyl-derived ring substituents (referred to earlier as BDT(T) motifs). In recent work, we showed that ring-substituted BDTs can help mediate the development of the $\mathrm{BHJ}$ morphologies between polymer donors and fullerene acceptors in $\mathrm{BHJ}$ solar cells. ${ }^{58}$ Turning to $\mathbf{S M}_{4}$, Table 1 shows that "as-cast"
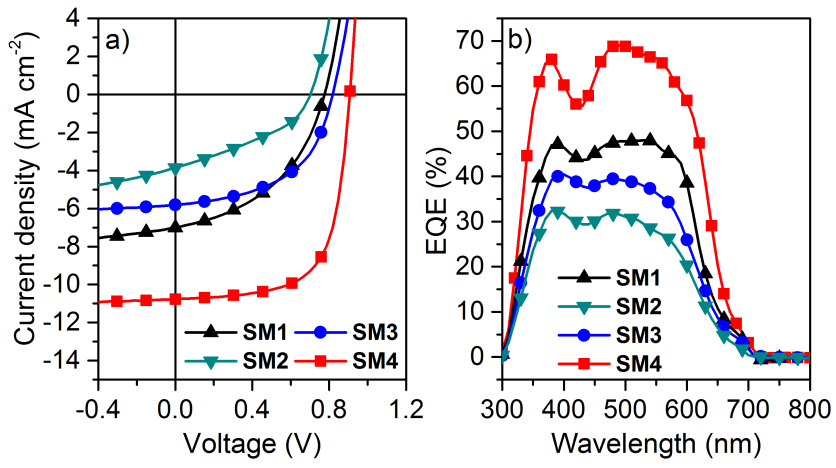

Figure 4. (a) Characteristic $J$ - $V$ curves of optimized BHJ solar cells fabricated from SM1-4 (cast from CB, processing conditions detailed in Table 1); AM1.5G solar illumination (100 $\mathrm{mW} / \mathrm{cm}^{2}$ ). (b) EQE spectra of the devices fabricated from SM1-4 under optimized conditions. Integrated EQEs are in agreement $\left( \pm 0.4 \mathrm{~mA} / \mathrm{cm}^{2}\right)$ with the $J_{\mathrm{sc}}$ values reported in Table 1.
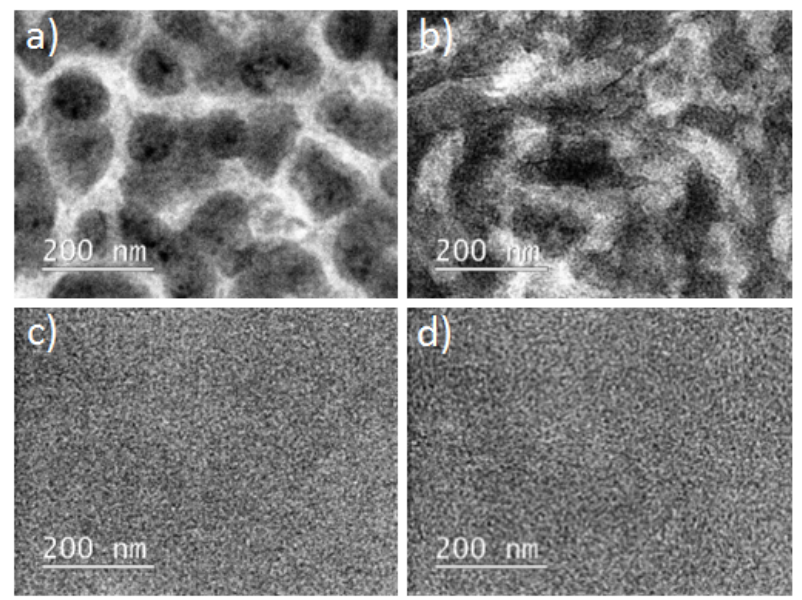

Figure 5. Bright-field TEM images of the BHJ thin-film morphologies of $\mathbf{S M}_{3}$ and $\mathbf{S M}_{4}$. (a) $\mathbf{S M}_{3}$ cast from $\mathrm{CB}$, no DIO additive; (b) $\mathrm{SM}_{3}$ cast from CB, $0.5 \% \mathrm{DIO}(\mathrm{v} / \mathrm{v})$; (c) $\mathbf{S M}_{4}$ cast from CB, no DIO; (d) $\mathbf{S M}_{4}$ cast from CB, o.2\% DIO (v/v).

BHJ solar cells achieve significantly higher PCEs of $\mathbf{2 . 4} \%$ (Avg.) compared to SM1-3-based "as-cast" devices, combining a large $V_{\mathrm{OC}}$ of $0.95 \mathrm{~V}$ in agreement with the PESAestimated IP of $\mathbf{S M}_{4}$ (ca. 5.1 eV), and an increase of over three-fold in $J_{\mathrm{SC}}\left(7.0 \mathrm{~mA} / \mathrm{cm}^{2}\right)$. Here, devices made with

DIO (0.2\%, v/v) achieved PCEs of up to ca. 6.5\% (Max.), correlated to a net increase in $J_{\mathrm{SC}}\left(10.5 \mathrm{~mA} / \mathrm{cm}^{2}\right)$ and $\mathrm{FF}$ (ca. $67 \%$ ). The high $J_{\mathrm{SC}}$ values achieved with $\mathbf{S M}_{4}$-based BHJ solar cells (Fig. 4a) are consistent with the external quantum efficiency (EQE) spectra (Fig. 4b); with $\mathbf{S M}_{4}$ based devices showing EQE values higher by $>20 \%$ in the range $350-600 \mathrm{~nm}$ (peaking at $70 \%$ ), while the EQE responses of SM1-3-based devices remains under 50\% in the same range, in agreement with the modest $J_{\mathrm{SC}}$ values of 3.6-6.7 $\mathrm{mA} / \mathrm{cm}^{2}$ estimated from the $J-V$ plots (Fig. 4a). Integrated EQEs are in agreement $\left( \pm 0.4 \mathrm{~mA} / \mathrm{cm}^{2}\right)$ with the $J_{\mathrm{sc}}$ values reported in Table 1 . The $\mathrm{BHJ}$ morphologies of "as-cast" and optimized devices made from $\mathbf{S M}_{4}$ were inspected by bright-field TEM and compared to those obtained for $\mathbf{S M}_{3}$-based devices; TEM images shown in Figure $5 \mathrm{c}$ and $5 \mathrm{~d}$. Here, the thin-film morphologies of 
SM4-based devices are well mixed compared to those discussed earlier for $\mathbf{S M}_{3}$, indicating that the ringsubstituted BDT(T) motifs play a critical role in mediating the development of the BHJ morphologies. These observations are in agreement with the high $J_{\mathrm{SC}}$ values achieved with $\mathbf{S M}_{4}$-based devices (Table 1 and Fig. 4a), and the near-complete photoluminescence (PL) quenching of the $\mathrm{SM}_{4}$ analogue in the presence of $\mathrm{PC}_{71} \mathrm{BM}$ (quenching efficiency of ca. 99.2\%; Fig. S9) - indicating that morphological aspects are not limiting the diffusion of photogenerated excitons to the $\mathrm{SM}$ - and $\mathrm{PC}_{71} \mathrm{BM}$-rich domain interfaces.

Important morphological differences between $\mathrm{BHJ}$ thin films often correlate with distinct charge transport patterns, impacting the figures of merit of OPV devices. ${ }^{53,59}$ To probe carrier effects, we measured the hole mobilities of $\mathbf{S M}_{3}$ and $\mathbf{S M}_{4}$ in optimized BHJ thin films; values inferred from the space charge limited current (SCLC) model (cf. details in SI). Figure 6 shows the dark current densities of the optimized $\mathrm{BHJ}$ thin films in hole-only diodes (ITO/ $\mathrm{MoO}_{3} / \mathrm{SM}: \mathrm{PC}_{71} \mathrm{BM} / \mathrm{MoO}_{3} / \mathrm{Ag}$ ) as a function of applied effective field (fits for various $\mathrm{BHJ}$ thicknesses in Fig. Sio). Our analyses indicate that the zero-field hole mobilities of $\mathbf{S M}_{4}$-based BHJs are one order of magnitude larger than those of the $\mathbf{S M}_{3}$-based counterparts: $1.5 \times 10^{-5}$ $\mathrm{cm}^{2} \mathrm{~V}^{-1} \mathrm{~s}^{-1}$ vs. $1.5 \times 10^{-6} \mathrm{~cm}^{2} \mathrm{~V}^{-1} \mathrm{~s}^{-1}$, respectively; results consistent with the marked PCE differences in $\mathbf{S M}_{4^{-}}$and SM3-based optimized BHJ solar cells: 6.3\% (Avg.; Max. 6.5\%) vs. $2.3 \%$ (Avg.; Max. 2.5\%).

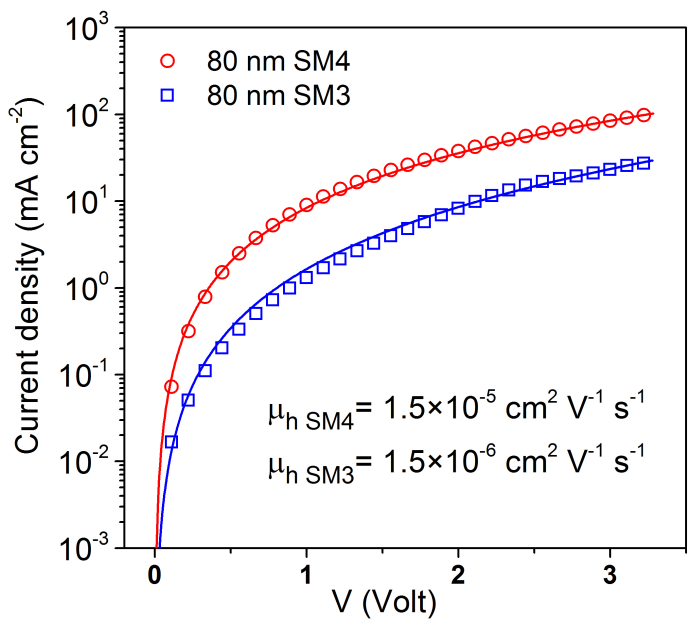

Figure 6. Dark $J-V$ curves for hole-only diodes made with optimized BHJ thin films with $\mathbf{S M}_{\mathbf{3}}$ (square) and $\mathbf{S M}_{\mathbf{4}}$ (circle) as SM donors; diode configuration: ITO/ $\mathrm{MoO}_{3} / \mathrm{SM}: \mathrm{PC}_{71} \mathrm{BM} /$ $\mathrm{MoO}_{3} / \mathrm{Ag}$ (film thickness: $8 \mathrm{o} \mathrm{nm}$ ). Data obtained for different film thicknesses are provided in SI (Fig. Sio). The experimental data is fitted using the single-carrier SCLC model (solid lines; cf. details in SI).

Beyond morphological considerations, charge transport also critically depends on how $\pi$-conjugated SM systems self-assemble and pack in thin films. ${ }^{60}$ In parallel, packing effects can factor into the development of the $\mathrm{BHJ}$ morphology. To examine those effects and determine if BDT(T) motifs in $\mathbf{S M}_{4}$ affect molecular packing, we turned to ${ }^{1} \mathrm{H}^{-1} \mathrm{H}$ double quantum-single quantum (DQSQ) solid-state NMR analyses (cf. details in SI). The
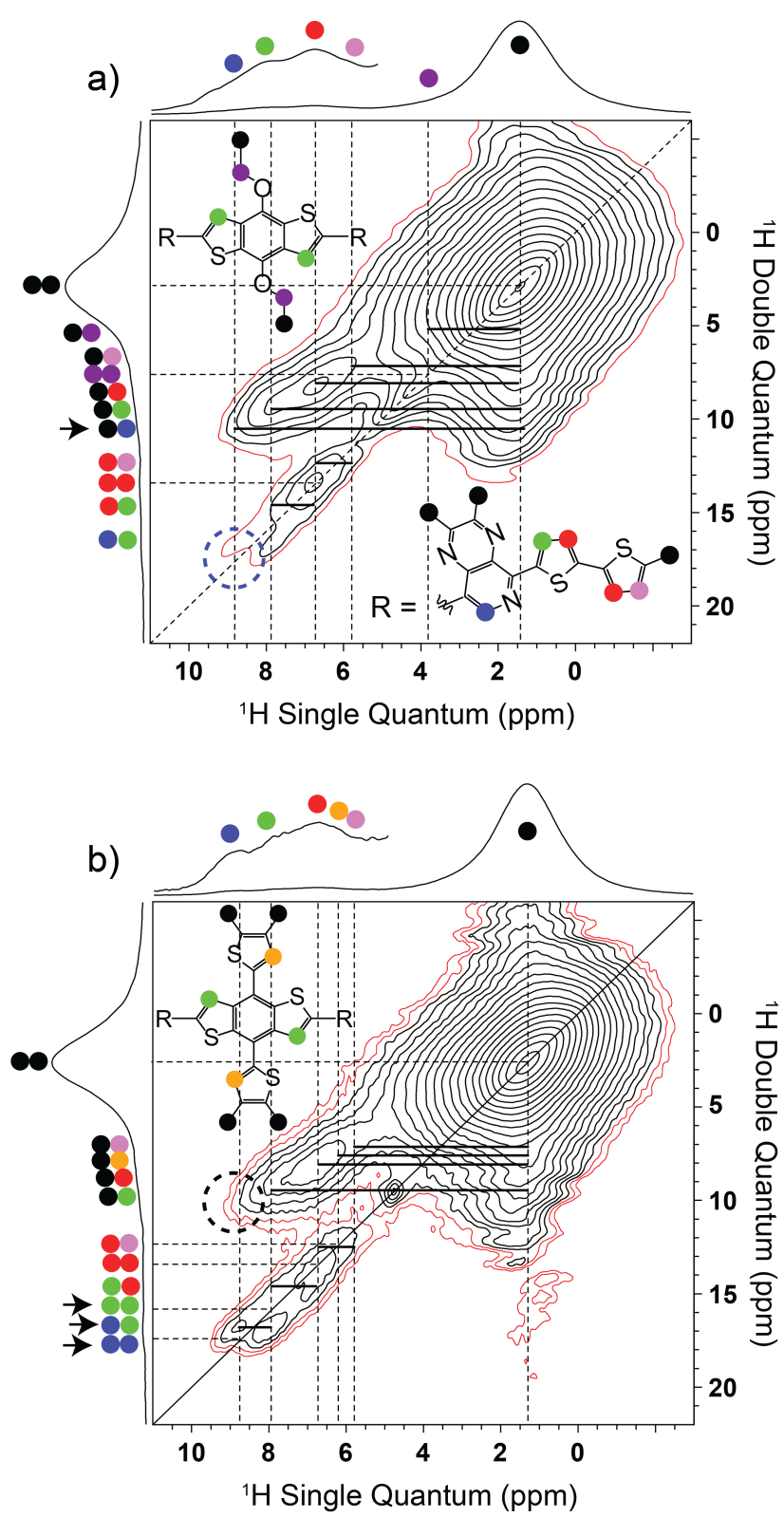

Figure 7. ${ }^{1} \mathrm{H}-{ }^{1} \mathrm{H}$ DQ-SQ NMR spectra of the SM donors (a) $\mathbf{S M}_{3}$ and (b) $\mathbf{S M}_{4}$; samples prepared from thin films (cf. details in SI). The color-coded assignment of the protons in the chemical structures of the SM donors is shown in insets. The red contours depict the same spectra recorded at an intensity level that is one-step lower than that used for the black contours; lower intensity levels correlating with lower proton-proton interactions. The arrows near the markers indicate key differences between the spectra (detailed in the manuscript text).

correlations produced by these experiments reflect the spatial connectivity of locally proximate $(<4 \AA)$ protons, which provides important insights into the molecular packing within $\pi$-conjugated stacks. ${ }^{50}$ Figure 7 shows the ${ }^{1} \mathrm{H}_{-}{ }^{1} \mathrm{H}$ DQ-SQ NMR spectra of $\mathbf{S M}_{3}$ and $\mathbf{S M}_{4}$; the colorcoded assignment of the protons in the chemical structures of the SM donors is shown in insets. As shown in the single quantum axes, peaks from the SM backbones are relatively well resolved while the alkyl chains (labelled black) on the different motifs merge into a single broad 
peak. Expectedly, the ${ }^{1} \mathrm{H}$ peak of the PP motif (labeled blue) shows as the most downfield chemical shift in both SM spectra. Since the PP protons are distant by $>4 \AA$ from their direct (intramolecular) neighbors in adjacent PP motifs, any double quantum signal on the plot diagonal at that chemical shift indicates the presence of an intermolecular interaction with a cofacially packed SM neighbor. As shown in Figure $7 \mathrm{a}$, the PP proton in $\mathbf{S M}_{3}$ shows a stronger correlation with the side-chain protons (blackblue; emphasized by arrows) and a weaker correlation with backbone-appended protons (indicated by the blue dotted circle). In contrast, as shown in Figure $7 \mathrm{~b}$, the PP proton in $\mathbf{S M}_{4}$ shows a significantly more pronounced correlation with backbone-appended protons (bluegreen, blue-blue; emphasized by arrows), and a weaker correlation with the side chain protons (indicated by the black dotted circle). In parallel, we note that ${ }^{1} \mathrm{H}-{ }^{1} \mathrm{H}$ intermolecular backbone interactions in $\mathbf{S M}_{4}$ are comparatively more prominent than in $\mathbf{S M}_{3}$ (cf. details in Fig. 7 caption), suggesting close packing driven by $\pi-\pi$ interactions in thin films of $\mathbf{S M}_{4}$. These differences in molecular packing patterns between $\mathbf{S M}_{3}$ and $\mathbf{S M}_{4}$ are schematically illustrated in Figure 8.

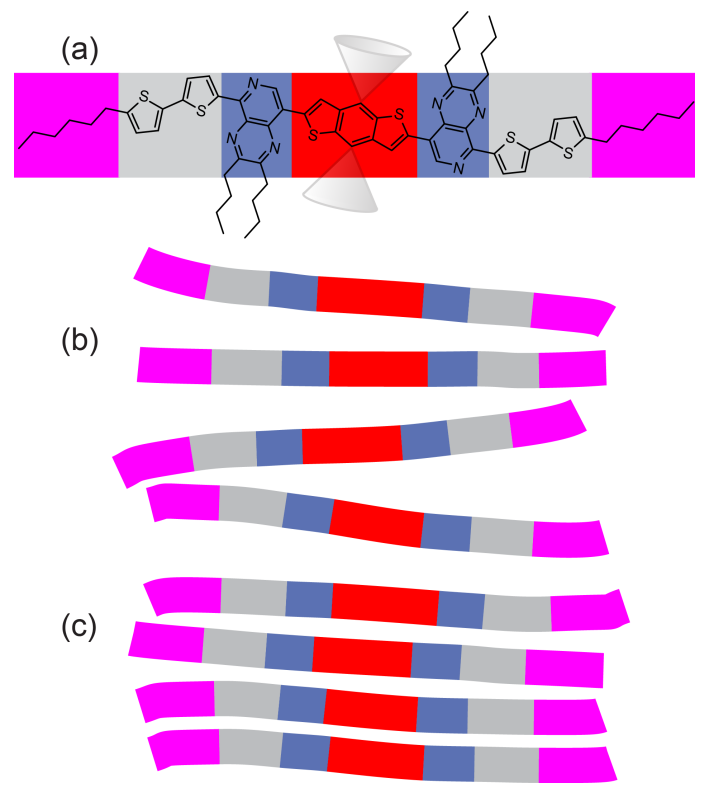

Figure 8. Schematic representation of the variations in molecular packing inferred from the ${ }^{1} \mathrm{H}-{ }^{1} \mathrm{H}$ DQ-SQ NMR spectra of $\mathrm{SM}_{3}$ and $\mathrm{SM}_{4}$; subset (a) shows the general structure of the SM donors. Subset (b) depicts the lesser backbonecorrelated extent of packing in $\mathbf{S M}_{3}$-based thin films, and subset (c) emphasizes the close molecular packing in $\mathbf{S M}_{4}$ based thin films.

Overall, these analyses indicate that $\mathbf{S M}_{3}$ and $\mathbf{S M}_{4}$ adopt distinct self-assembly patterns, implying that BDT(T) motifs in $\mathbf{S M}_{4}$ impact molecular packing. The distinct self-assembly patterns and packing effects in $\mathbf{S M}_{3}$ and $\mathrm{SM}_{4}$ can be expected to contribute to the BHJ morphology and charge transport differences discussed earlier. Lastly, we note that the extent and composition of the mixed SM-fullerene phase in SM-based BHJs can be considered as a morphological effect, ${ }^{62-64}$ and may also affect the $J_{S C}$ and $F F$ values of the optimized devices, however these detailed analyses are beyond the scope of this study.

\section{Conclusions}

In summary, we have shown that in benzo[1,2-b:4,5$b^{\prime}$ ]dithiophene-pyrido[3,4-b]pyrazine SM donors (SM1-4), ring-substituted $\mathrm{BDT}(\mathrm{T})$ core units are critical to achieving efficient material and $\mathrm{BHJ}$ solar cell characteristics. While practically unexplored in SM designs, alkylsubstituted PP acceptor motifs can contribute to improving SM solubility and film-forming properties. In these systems, the pattern of substituents appended to the $\pi$ conjugated main chain critically impacts (i) molecular packing, and (ii) thin-film morphologies and charge transport in BHJ solar cells. We found that, with the appropriate side-chain pattern, the ring-substituted analogue $\mathrm{SM}_{4}$ stands out: achieving efficiencies of ca. $6.5 \%$ with $\mathrm{PC}_{71} \mathrm{BM}$, and fine-scale morphologies comparable to those obtained with some of the best-performing polymer donors in BHJ solar cells. ${ }^{1} \mathrm{H}-{ }^{1} \mathrm{H}$ DQ-SQ NMR analyses show a distinct self-assembly pattern for $\mathbf{S M}_{4}$, expected to factor into the development of the BHJ morphology.

In parallel, we note that - in comparison with the lowbandgap dithieno[3,2-b:2',3'-d] silole-benzo[ $c][1,2,5]$ thiadiazole (N- or F-substituted) SM analogues $\left(E_{\mathrm{opt}} \sim 1.5 \mathrm{eV}\right)-$ benzo[1,2- $\left.b: 4,5-b^{\prime}\right]$ di-thiophene-pyrido[3,4-b]pyrazine SM donors are wider-bandgap $\left(E_{\mathrm{opt}} \sim 1.9 \mathrm{eV}\right.$; similar to that of $\mathrm{P}_{3} \mathrm{HT}$ ) and promising systems for use in the highbandgap cell of SM multi-junction solar cells with complementary absorbers.

\section{Experimental Section}

Material Characterizations. All compounds were characterized by NMR spectroscopy on Bruker Avance III Ultrashield Plus instruments using a 400, 500, 600 or $700 \mathrm{MHz}$ proton frequency. High-resolution mass spectrometry (HRMS) data was recorded using a Thermo Scientific - LTQ Velos Orbitrap MS. Information on materials, synthetic methods and protocols for the syntheses of SM1-4 are detailed in the Supporting Information (SI). Further details on PESA, UV-vis, TGA, DSC, and solid-state NMR instrumentation and experimental conditions are developed in the SI.

Computational Analyses. All density functional theory (DFT) calculations were performed at the $\mathrm{B}_{3} \mathrm{LYP} / 6-31 \mathrm{G}(\mathrm{d}, \mathrm{p})$ level of theory with the Gaussian og (Revision C.o1) software. $B_{3}$ LYP functional was chosen for the potential energy surface (PES) scans in order to maintain consistency with the smallmolecule orbital density calculations. Additional details and references can be found in the SI.

Device Testing Protocols. The solar cells were prepared on glass substrates with tin-doped indium oxide (ITO, $15 \Omega \mathrm{sq}^{-1}$ ) patterned on the surface (device area: $0.1 \mathrm{~cm}^{2}$ ). Information on substrate preparation, active layer and contact depositions are detailed in the SI. Solar cell $J-V$ measurements were performed in the glovebox with a Keithley 2400 source meter and an Oriel Sol3A Class AAA solar simulator calibrated to 1 sun, AM1.5 G, with a KG-5 silicon reference cell certified by Newport. The external quantum efficiency (EQE) measurements were performed at zero bias by illuminating the device with monochromatic light supplied from a Xenon arc lamp in combination with a dual-grating monochromator. The 
number of photons incident on the sample was calculated for each wavelength by using a silicon photodiode calibrated by NIST. Additional details on various active layer deposition conditions, TEM and PL instrumentation, and carrier mobility measurements are developed in the SI.

\section{ASSOCIATED CONTENT}

\section{Supporting Information}

Detailed experimental methods, characterization, and additional figures and tables. This material is available free of charge via the Internet at http://pubs.acs.org.

\section{AUTHOR INFORMATION}

\section{Corresponding Author}

*E-mail: pierre.beaujuge@kaust.edu.sa

\section{Author Contributions}

${ }^{\ddagger}$ These authors contributed equally.

\section{Notes}

The authors declare no competing financial interest.

\section{ACKNOWLEDGMENT}

This publication is based upon work supported by the King Abdullah University of Science and Technology (KAUST) Office of Sponsored Research (OSR) under Award No. CRG_R2_13_BEAU_KAUST_1. The authors acknowledge concurrent support under Baseline Research Funding from KAUST. The authors thank KAUST ACL for technical support in the mass spectrometry analyses. M.R.H. acknowledges the Villum Foundation, Denmark under the Young Investigator Programme (VKRo23122).

\section{REFERENCES}

(1) Sun, Y.; Welch, G. C.; Leong, W. L.; Takacs, C. J.; Bazan, G. C.; Heeger, A. J., Solution-Processed Small-Molecule Solar Cells with 6.7\% Efficiency. Nat. Mater. 2012, 11, 44-48.

(2) Van der Poll, T. S.; Love, J. A.; Nguyen, T. Q.; Bazan, G. C., Non-Basic High-Performance Molecules for Solution-Processed Organic Solar Cells. Adv. Mater. 2o12, 24, 3646-3649.

(3) Zhang, Q.; Kan, B.; Liu, F.; Long, G.; Wan, X.; Chen, X.; Zuo, Y.; Ni, W.; Zhang, H.; Li, M.; Hu, Z.; Huang, F.; Cao, Y.; Liang, Z.; Zhang, M.; Russell, T. P.; Chen, Y., Small-Molecule Solar Cells with Efficiency over 9\%. Nat. Photonics 2014, 9, 35-41.

(4) Coughlin, E. J.; Henson, Z. B.; Welch, G. C.; Bazan, G. C., Design and Synthesis of Molecular Donors for SolutionProcessed High-Efficiency Organic Solar Cells. Acc. Chem. Res. 2014, 47, 257-270.

(5) Kan, B.; Li, M.; Zhang, Q.; Liu, F.; Wan, X.; Wang, Y.; Ni, W.; Long, G.; Yang, X.; Feng, H.; Zuo, Y.; Zhang, M.; Huang, F.; Cao, Y.; Russell, T. P.; Chen, Y., A Series of Simple Oligomer-Like Small Molecules Based on Oligothiophenes for SolutionProcessed Solar Cells with High Efficiency. J. Am. Chem. Soc. 2015, 137, 3886-3893.

(6) Zhou, C.; Liang, Y.; Liu, F.; Sun, C.; Huang, X.; Xie, Z.; Huang, F.; Roncali, J.; Russell, T. P.; Cao, Y., Chain Length Dependence of the Photovoltaic Properties of Monodisperse Donor-Acceptor Oligomers as Model Compounds of Polydisperse Low Band Gap Polymers. Adv. Funct. Mater. 2014, 24, 7538-7547.

(7) Lai, L. F.; Love, J. A.; Sharenko, A.; Coughlin, J. E.; Gupta, V.; Tretiak, S.; Nguyen, T. Q.; Wong, W. Y.; Bazan, G. C., Topological Considerations for the Design of Molecular Donors with Multiple Absorbing Units. J. Am. Chem. Soc. 2014, 136, 55915594 .

(8) Perez, L. A.; Chou, K. W.; Love, J. A.; van der Poll, T. S.; Smilgies, D. M.; Nguyen, T. Q.; Kramer, E. J.; Amassian, A.; Bazan, G. C., Solvent Additive Effects on Small Molecule Crystallization in Bulk Heterojunction Solar Cells Probed During Spin Casting. Adv. Mater. 2013, 25, 6380-6384.

(9) Welch, G. C.; Perez, L. A.; Hoven, C. V.; Zhang, Y.; Dang, X.D.; Sharenko, A.; Toney, M. F.; Kramer, E. J.; Nguyen, T.-Q.; Bazan, G. C., A Modular Molecular Framework for Utility in Small-Molecule Solution-Processed Organic Photovoltaic Devices. J. Mater. Chem. 2011, 21, 12700-12709.

(10) Bartelt, J. A.; Lam, D.; Burke, T. M.; Sweetnam, S. M.; McGehee, M. D., Charge-Carrier Mobility Requirements for Bulk Heterojunction Solar Cells with High Fill Factor and External Quantum Efficiency >90\%. Adv. Energy Mater. 2015, 5, 1500577. (11) Li, W.; Albrecht, S.; Yang, L.; Roland, S.; Tumbleston, J. R.; McAfee, T.; Yan, L.; Kelly, M. A.; Ade, H.; Neher, D.; You, W., Mobility-Controlled Performance of Thick Solar Cells Based on Fluorinated Copolymers. J. Am. Chem. Soc. 2014, 136, 1556615576 .

(12) Würfel, U.; Neher, D.; Spies, A.; Albrecht, S., Impact of Charge Transport on Current-Voltage Characteristics and Power-Conversion Efficiency of Organic Solar Cells. Nat. Commun. 2015, 6, 6951.

(13) Kan, B.; Zhang, Q.; Li, M.; Wan, X.; Ni, W.; Long, G.; Wang, Y.; Yang, X.; Feng, H.; Chen, Y., Solution-Processed Organic Solar Cells Based on Dialkylthiol-Substituted Benzodithiophene Unit with Efficiency near 10\%. J. Am. Chem. Soc. 2014, 136, 1552915532.

(14) Zhou, J.; Wan, X.; Liu, Y.; Zuo, Y.; Li, Z.; He, G.; Long, G.; Ni, W.; Li, C.; Su, X.; Chen, Y., Small Molecules Based on Benzo[1,2$\left.b: 4,5^{-} b^{\prime}\right]$ Dithiophene Unit for High-Performance SolutionProcessed Organic Solar Cells. J. Am. Chem. Soc. 2012, 134, 1634516351.

(15) Zhou, J.; Zuo, Y.; Wan, X.; Long, G.; Zhang, Q.; Ni, W.; Liu, Y.; Li, Z.; He, G.; Li, C.; Kan, B.; Li, M.; Chen, Y., SolutionProcessed and High-Performance Organic Solar Cells Using Small Molecules with a Benzodithiophene Unit. J. Am. Chem. Soc. 2013, 135, 8484-8487.

(16) Guerrero, A.; Loser, S.; Garcia-Belmonte, G.; Bruns, C. J.; Smith, J.; Miyauchi, H.; Stupp, S. I.; Bisquert, J.; Marks, T. J., Solution-Processed Small Molecule:Fullerene BulkHeterojunction Solar Cells: Impedance Spectroscopy Deduced Bulk and Interfacial Limits to Fill-Factors. Phys. Chem. Chem. Phys. 2013, 15, 16456-16462.

(17) Harschneck, T.; Zhou, N.; Manley, E. F.; Lou, S. J.; Yu, X.; Butler, M. R.; Timalsina, A.; Turrisi, R.; Ratner, M. A.; Chen, L. X.; Chang, R. P.; Facchetti, A.; Marks, T. J., Substantial Photovoltaic Response and Morphology Tuning in Benzo[1,2B:6,5-b']Dithiophene (Bbdt) Molecular Donors. Chem. Commun. 2014, 50, 4099-4101.

(18) Liu, X.; Sun, Y.; Perez, L. A.; Wen, W.; Toney, M. F.; Heeger, A. J.; Bazan, G. C., Narrow-Band-Gap Conjugated Chromophores with Extended Molecular Lengths. J. Am. Chem. Soc. 2012, 134, 20609-20612.

(19) Liu, X.; Sun, Y.; Hsu, B. B.; Lorbach, A.; Qi, L.; Heeger, A. J.; Bazan, G. C., Design and Properties of Intermediate-Sized Narrow Band-Gap Conjugated Molecules Relevant to SolutionProcessed Organic Solar Cells. J. Am. Chem. Soc. 2014, 136, 56975708.

(20) Love, J. A.; Nagao, I.; Huang, Y.; Kuik, M.; Gupta, V.; Takacs, C. J.; Coughlin, J. E.; Qi, L.; van der Poll, T. S.; Kramer, E. J.; Heeger, A. J.; Nguyen, T. Q.; Bazan, G. C., Silaindacenodithiophene-Based Molecular Donor: Morphological Features and Use in the Fabrication of Compositionally Tolerant, High-Efficiency Bulk Heterojunction Solar Cells. J. Am. Chem. Soc. 2014, 136, 3597-36o6. 
(21) Treat, N. D.; Nekuda Malik, J. A.; Reid, O.; Yu, L.; Shuttle, C. G.; Rumbles, G.; Hawker, C. J.; Chabinyc, M. L.; Smith, P.; Stingelin, N., Microstructure Formation in Molecular and Polymer Semiconductors Assisted by Nucleation Agents. Nat. Mater. 2013, 12, 628-633.

(22) Bai, H.; Wang, Y.; Cheng, P.; Li, Y.; Zhu, D.; Zhan, X., Acceptor-Donor-Acceptor Small Molecules Based on Indacenodithiophene for Efficient Organic Solar Cells. ACS Appl. Mater. Interfaces 2014, 6, 8426-8433.

(23) Lee, O. P.; Yiu, A. T.; Beaujuge, P. M.; Woo, C. H.; Holcombe, T. W.; Millstone, J. E.; Douglas, J. D.; Chen, M. S.; Frechet, J. M., Efficient Small Molecule Bulk Heterojunction Solar Cells with High Fill Factors Via Pyrene-Directed Molecular Self-Assembly. Adv. Mater. 2011, 23, 5359-5363.

(24) Sun, K.; Xiao, Z.; Lu, S.; Zajaczkowski, W.; Pisula, W.; Hanssen, E.; White, J. M.; Williamson, R. M.; Subbiah, J.; Ouyang, J.; Holmes, A. B.; Wong, W. W.; Jones, D. J., A Molecular Nematic Liquid Crystalline Material for HighPerformance Organic Photovoltaics. Nat. Commun. 2015, 6, 6013. (25) Wang, J.-L.; Wu, Z.; Miao, J.-S.; Liu, K.-K.; Chang, Z.-F.; Zhang, R.-B.; Wu, H.-B.; Cao, Y., Solution-Processed Diketopyrrolopyrrole-Containing Small-Molecule Organic Solar Cells with 7.0\% Efficiency: In-Depth Investigation on the Effects of Structure Modification and Solvent Vapor Annealing. Chem. Mater. 2015, 27, 4338-4348.

(26) Takacs, C. J.; Sun, Y.; Welch, G. C.; Perez, L. A.; Liu, X.; Wen, W.; Bazan, G. C.; Heeger, A. J., Solar Cell Efficiency, SelfAssembly, and Dipole-Dipole Interactions of Isomorphic Narrow-Band-Gap Molecules. J. Am. Chem. Soc. 2012, 134, 1659716606.

(27) He, X.; Cao, B.; Hauger, T. C.; Kang, M.; Gusarov, S.; Luber, E. J.; Buriak, J. M., Donor-Acceptor Small Molecules for Organic Photovoltaics: Single-Atom Substitution (Se or S). ACS Appl. Mater. Interfaces 2015, 7, 8188-8199.

(28) Patra, D.; Huang, T. Y.; Chiang, C. C.; Maturana, R. O.; Pao, C. W.; Ho, K. C.; Wei, K. H.; Chu, C. W., 2-Alkyl-5-ThienylSubstituted Benzo[1,2-b:4,5- $b$ ']Dithiophene-Based Donor Molecules for Solution-Processed Organic Solar Cells. ACS Appl. Mater. Interfaces 2013, 5, 9494-9500.

(29) Weidelener, M.; Wessendorf, C. D.; Hanisch, J.; Ahlswede, E.; Gotz, G.; Linden, M.; Schulz, G.; Mena-Osteritz, E.; Mishra, A.; Bauerle, P., Dithienopyrrole-Based Oligothiophenes for Solution-Processed Organic Solar Cells. Chem. Commun. 2013, 49, $10865-10867$.

(30) Ren, Y.; Hailey, A. K.; Hiszpanski, A. M.; Loo, Y.-L., Isoindigo-Containing Molecular Semiconductors: Effect of Backbone Extension on Molecular Organization and Organic Solar Cell Performance. Chem. Mater. 2014, 26, 6570-6577.

(31) Price, S. C.; Stuart, A. C.; Yang, L.; Zhou, H.; You, W., Fluorine Substituted Conjugated Polymer of Medium Band Gap Yields $7 \%$ Efficiency in Polymer-Fullerene Solar Cells. J. Am. Chem. Soc. 2011, 133, 4625-4631.

(32) Andersson, M.; Bo, Z.; Liu, Z.; Ingana, O.; Qin, R.; Li, W.; Li, C.; Du, C.; Veit, C.; Schleiermacher, H.; Wuerfel, U.; Zhang, F., A Planar Copolymer for High Efficiency Polymer Solar Cells. J. Am. Chem. Soc. 2009, 131, 14612-14613.

(33) Bouffard, J.; Swager, T., Fluorescent Conjugated Polymers That Incorporate Substituted

2,1,3-Benzooxadiazole and 2,1,3-Benzothiadiazole Units. Macromolecules 2008, 41, 5559-5562.

(34) Xu, X.; Wang, C.; Bäcke, O.; James, D.; Bini, K.; Olsson, E.; Andersson, M.; Fahlman, M.; Wang, E., Pyrrolo[3,4g]quinoxaline-6,8-dione-based Conjugated Copolymers for Bulk Heterojunction Solar Cells with High Photovoltages. Polym. Chem. 2015, 6, 4624-4633.

(35) Tessarolo, M.; Gedefaw, D.; Bolognesi, M.; Liscio, F.; Henriksson, P.; Zhuang, W.; Milita, S.; Muccini, M.; Wang, E.; Seri, M.; Andersson, M., Structural Tuning of Quinoxaline- benzodithiophene Copolymers via Alkyl Side Chain Manipulation: Synthesis, Characterization and Photovoltaic Properties. J. Mater. Chem. A, 2014, 2, 11162-11170.

(36) Zhang, J.; Cai, W.; Huang, F.; Wang, E.; Zhong, C.; Liu, S.; Wang, M.; Duan, C.; Yang, T.; Cao, Y., Synthesis of QuinoxalineBased Donor-Acceptor Narrow-Band-Gap Polymers and Their Cyclized Derivatives for Bulk-Heterojunction Polymer Solar Cell Applications Macromolecules, 2011, 44, 894-901.

(37) Wang, E.; Hou, L.; Wang, Z.; Hellström, S.; Zhang, F.; Inganäs, O.; Anersson, M., An easily Synthesized Blue Polymer for High-Performance Polymer Solar Cells. Adv. Mater., 2010, 22, 5240-5244.

(38) Lee, B.-L.; Yamamoto, T., Syntheses of New Alternating CtType Copolymers of Thiophene and Pyrido[3,4-b]Pyrazine Units: Their Optical and Electrochemical Properties in Comparison with Similar Ct Copolymers of Thiophene with Pyridine and Quinoxaline. Macromolecules 1999, 32, 1375-1382.

(39) Kroon, R.; Gehlhaar, R.; Steckler, T. T.; Henriksson, P.; Mueller, C.; Bergqvist, J.; Hadipour, A.; Heremans, P.; Andersson, M. R., New Quinoxaline and Pyridopyrazine-Based Polymers for Solution-Processable Photovoltaics. Sol. Energy Mater. Sol. Cells 2012, 105, 280-286.

(40) Zhang, X.; Shim, J. W.; Tiwari, S. P.; Zhang, Q.; Norton, J. E.; Wu, P.-T.; Barlow, S.; Jenekhe, S. A.; Kippelen, B.; Bredas, J.L.; Marder, S. R., Dithienopyrrole-Quinoxaline/Pyridopyrazine Donor-Acceptor Polymers: Synthesis and Electrochemical, Optical, Charge-Transport, and Photovoltaic Properties. J. Mater. Chem. 2011, 21, 4971-4982.

(41) Yuan, M.-C.; Chiu, M.-Y.; Chiang, C.-M.; Wei, K.-H., Synthesis and Characterization of Pyrido[3,4-b]Pyrazine-Based Low-Bandgap Copolymers for Bulk Heterojunction Solar Cells. Macromolecules 2010, 43, 6270-6277.

(42) Zhang, F.; Jonforsen, M.; Johansson, D. M.; Andersson, M. R.; Inganas, O., Photodiodes and Solar Cells Based on the NType Polymer Poly(Pyridopyrazine Vinylene) as Electron Acceptor. Synth. Met. 2003, 138, 555-560.

(43) Roncali, J.; Leriche, P.; Blanchard, P., Molecular Materials for Organic Photovoltaics: Small Is Beautiful. Adv. Mater. 2014, $26,3821-3838$.

(44) Zhang, X.; Mao, J.; Wang, D.; Li, X.; Yang, J.; Shen, Z.; Wu, W.; Li, J.; Agren, H.; Hua, J., Comparative Study on Pyrido[3,4B]Pyrazine-Based Sensitizers by Tuning Bulky Donors for DyeSensitized Solar Cells. ACS Appl. Mater. Interfaces 2015, 7, 276o2771.

(45) Ying, W.; Yang, J.; Wielopolski, M.; Moehl, T.; Moser, J.-E.; Comte, P.; Hua, J.; Zakeeruddin, S. M.; Tian, H.; Graetzel, M., New Pyrido[3,4-b]Pyrazine-Based Sensitizers for Efficient and Stable Dye-Sensitized Solar Cells. Chem. Sci. 2014, 5, 206-214.

(46) Li, X.; Cui, S.; Wang, D.; Zhou, Y.; Zhou, H.; Hu, Y.; Liu, J.g.; Long, Y.; Wu, W.; Hua, J.; Tian, H., New Organic DonorAcceptor-П-Acceptor Sensitizers for Efficient Dye-Sensitized Solar Cells and Photocatalytic Hydrogen Evolution under Visible-Light Irradiation. ChemSusChem 2014, 7, 2879-2888.

(47) Shi, Q.; Chen, W.-Q.; Xiang, J.; Duan, X.-M.; Zhan, X., A Low-Bandgap Conjugated Polymer Based on Squaraine with Strong Two-Photon Absorption. Macromolecules 2011, 44, 37593765 .

(48) Cabanetos, C.; El Labban, A.; Bartelt, J. A.; Douglas, J. D.; Mateker, W. R.; Frechet, J. M.; McGehee, M. D.; Beaujuge, P. M., Linear Side Chains in Benzo[1,2-b:4,5- $b$ ']DithiopheneThieno[3,4-C]Pyrrole-4,6-Dione Polymers Direct Self-Assembly and Solar Cell Performance. J. Am. Chem. Soc. 2013, 135, 46564659 .

(49) Warnan, J.; Cabanetos, C.; Bude, R.; El Labban, A.; Li, L.; Beaujuge, P. M., Electron-Deficientn-Alkyloyl Derivatives of Thieno[3,4-c]Pyrrole-4,6-Dione Yield Efficient Polymer Solar Cells with Open-Circuit Voltages $>1$ V. Chem. Mater. 2014, 26, 2829-2835. 
(50) Warnan, J.; Cabanetos, C.; El Labban, A.; Hansen, M. R.; Tassone, C.; Toney, M. F.; Beaujuge, P. M., Ordering Effects in Benzo[1,2-b:4,5- $\left.b^{\prime}\right]$ Difuran-Thieno[3,4-c]Pyrrole-4,6-Dione Polymers with $>7 \%$ Solar Cell Efficiency. Adv. Mater. 2014, 26, 4357-4362.

(51) van Bavel, S. S.; Bärenklau, M.; de With, G.; Hoppe, H.; Loos, J., P 3 ht/Pcbm Bulk Heterojunction Solar Cells: Impact of Blend Composition and 3d Morphology on Device Performance. Adv. Funct. Mater. 2010, 20, 1458-1463.

(52) Kim, Y.; Cook, S.; Tuladhar, S. M.; Choulis, S. A.; Nelson, J.; Durrant, J. R.; Bradley, D. D. C.; Giles, M.; McCulloch, I.; Ha, C.S.; Ree, M., A Strong Regioregularity Effect in Self-Organizing Conjugated Polymer Films and High-Efficiency Polythiophene:Fullerene Solar Cells. Nat. Mater. 2oo6, 5, 197203.

(53) Choi, Y. S.; Shin, T. J.; Jo, W. H., Small Molecules Based on Thieno[3,4-c]Pyrrole-4,6-Dione for High Open-Circuit Voltage (Voc) Organic Photovoltaics: Effect of Different Positions of Alkyl Substitution on Molecular Packing and Photovoltaic Performance. ACS Appl. Mater. Interfaces 2014, 6, 20035-20042.

(54) Wessendorf, C. D.; Schulz, G. L.; Mishra, A.; Kar, P.; Ata, I.; Weidelener, M.; Urdanpilleta, M.; Hanisch, J.; Mena-Osteritz, E.; Lindén, M.; Ahlswede, E.; Bäuerle, P., Efficiency Improvement of Solution-Processed Dithienopyrrole-Based a-D-a Oligothiophene Bulk-Heterojunction Solar Cells by Solvent Vapor Annealing. Adv. Energy Mater. 2014, 4, 1400266.

(55) Henson, Z. B.; Welch, G. C.; van der Poll, T.; Bazan, G. C., Pyridalthiadiazole-Based Narrow Band Gap Chromophores. J. Am. Chem. Soc. 2012, 134, 3766-3779.

(56) Huang, Y.; Kramer, E. J.; Heeger, A. J.; Bazan, G. C., Bulk Heterojunction Solar Cells: Morphology and Performance Relationships. Chem. Rev. 2014, 114, 7006-7043.
(57) Lin, Y.; Li, Y.; Zhan, X., Small Molecule Semiconductors for High-Efficiency Organic Photovoltaics. Chem. Soc. Rev. 2012, 41, 4245-4272.

(58) Warnan, J.; El Labban, A.; Cabanetos, C.; Hoke, E. T.; Shukla, P. K.; Risko, C.; Brédas, J.-L.; McGehee, M. D.; Beaujuge, P. M., Ring Substituents Mediate the Morphology of PbdttpdPcbm Bulk-Heterojunction Solar Cells. Chem. Mater. 2014, 26, 2299-2306.

(59) Shen, S.; Jiang, P.; He, C.; Zhang, J.; Shen, P.; Zhang, Y.; Yi, Y.; Zhang, Z.; Li, Z.; Li, Y., Solution-Processable Organic Molecule Photovoltaic Materials with BithienylBenzodithiophene Central Unit and Indenedione End Groups. Chem. Mater. 2013, 25, 2274-2281.

(6o) Coropceanu, V.; Cornil, J.; Filho, D.; Olivier, Y.; Silbey, R.; Bredas, J. L., Charge Transport in Organic Semiconductors. Chem. Rev. 2007, 107, 926-952.

(61) Schnell, I.; Spiess, H. W., High-Resolution ih NMR Spectroscopy in the Solid State: Very Fast Sample Rotation and Multiple-Quantum Coherences. J. Magn. Reson. 2oo1, 151, 153227.

(62) Love, J. A.; Collins, S. D.; Nagao, I.; Mukherjee, S.; Ade, H.; Bazan, G. C.; Nguyen, T. Q., Interplay of Solvent Additive Concentration and Active Layer Thickness on the Performance of Small Molecule Solar Cells. Adv. Mater. 2014, 26, 7308-7316.

(63) Liu, Y.; Zhao, J.; Li, Z.; Mu, C.; Ma, W.; Hu, H.; Jiang, K.; Lin, H.; Ade, H.; Yan, H., Aggregation and Morphology Control Enables Multiple Cases of High-Efficiency Polymer Solar Cells. Nat. Commun. 2014, 5, 5293.

(64) Mukherjee, S.; Proctor, C. M.; Bazan, G. C.; Nguyen, T.-Q.; Ade, H., Significance of Average Domain Purity and Mixed Domains on the Photovoltaic Performance of High-Efficiency Solution-Processed Small-Molecule Bhj Solar Cells. Adv. Energy Mater. 2015, 5, 1500877. 


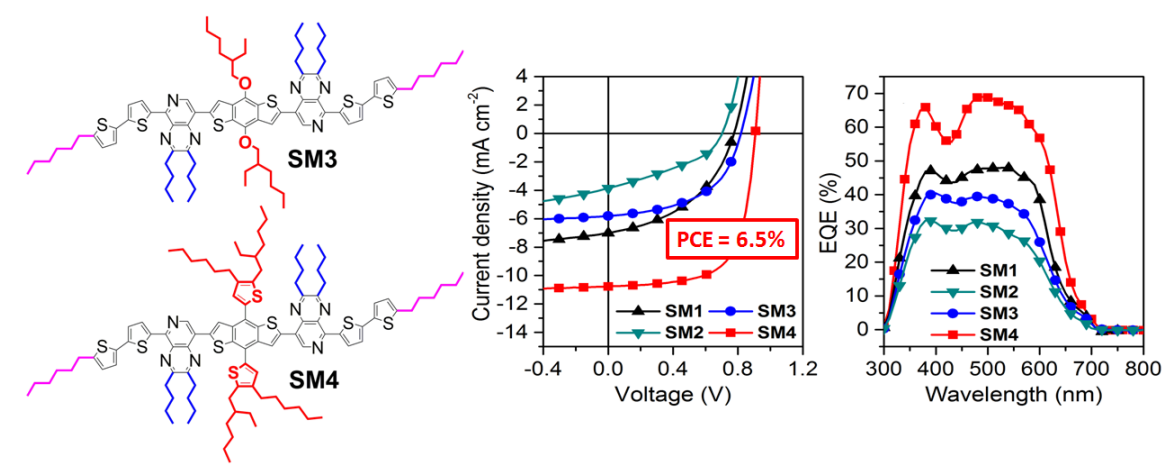

14

15

16

18

19

20 